\title{
APORTE DE LA ÉTICA LEVINASIANA AL CUIDADO EN LA TERAPIA CONTEXTUAL
}

\author{
CONTRIBUTION OF LEVINASIAN ETHICS TO CARE \\ IN THE CONTEXTUAL THERAPY
}

\author{
R. Joaquín Disla* \\ Instituto de Sexualidad Humana, Universidad Autónoma de Santo Domingo, \\ Santo Domingo - República Dominicana. \\ Cayetano Aranda \\ Universidad de Almería, \\ Almería - España. \\ Ramón Almánzar \\ Instituto de Sexualidad Humana, Universidad Autónoma de Santo Domingo, \\ Santo Domingo - República Dominicana.
}

Recibido abril de 2019/Received April, 2019

Aceptado julio de 2019/Accepted July, 2019

\begin{abstract}
RESUMEN
En este artículo se analiza la ética de Emmanuel Lévinas de cara al tema del cuidado en el acercamiento de la Terapia Contextual. Se eligieron para el mismo cinco de los temas claves que componen su propuesta filosófica, a saber: el Otro y su rostro; la relación ética; la responsabilidad; la asimetría de la relación y el sujeto ético levinasiano. Hasta la fecha se han identificado seis elementos que debe poseer un terapeuta contextual para poder aplicar la parcialidad multidireccional como método y actitud terapéutica que permite establecer una estructura que provee la seguridad para explorar, identificar, movilizar y ganar confianza residual en el desarrollo y aplicación de la Terapia Contextual. Estos seis elementos son: 1) Libertad; 2) Convicción; 3) Coraje; 4) Conocimiento y Habilidades; 5) Capacidad de empatía y 6) Habilidad para reclamar su propia existencia privada. El aporte de este trabajo consiste en añadir el séptimo elemento que debe poseer un terapeuta contextual: "La Capacidad para ofrecer cuidado".

Palabras Clave: Terapia Contextual, Ética relacional, Ética Levinasiana, Cuidado.
\end{abstract}

\begin{abstract}
In this article we analyze the ethics of Emmanuel Lévinas with regard to the care in the Contextual Therapy approach. Five of the key themes that make up his philosophical proposal were chosen for him, namely: the Other and his face; the ethical relationship; the responsibility; the asymmetry of the relation and the Levinasian ethical subject. To date, six elements have been identified that a contextual therapist must possess in order to apply multidirectional bias as a therapeutic method and attitude that allows establishing a structure that provides the security to explore, identify, mobilize and gain residual confidence in the development and application of Contextual Therapy. These six elements are: 1) Freedom; 2) Conviction; 3) Courage; 4) Knowledge and Skills; 5) Ability to empathy and 6) Ability to claim your own private existence. The contribution of this work is to add the seventh element that a contextual therapist must possess: "The capacity to offer care".
\end{abstract}

Key Words: Contextual Therapy, Relational Ethics, Levinasian Ethics, Care.

* Autor correspondiente / Corresponding author: joaquin.disla@gmail.com 


\section{INTRODUCCIÓN}

El creador de la Terapia Contextual (TC de ahora en adelante) fue el Dr. Ivan BoszormenyiNagy, y en su desarrollo participaron sus colaboradores. La TC está considerada como un acercamiento terapéutico amplio, tanto desde el punto de vista relacional como individual. De acuerdo a Ducommun (2002) la TC no es una forma de terapia individual o de terapia marital, tampoco constituye una versión clásica de la terapia familiar, sino que más bien, en su esencia, constituye una forma de terapia relacional.

Según este enfoque la conducta humana no cae simplemente bajo el control de necesidades biológicas, de impulsos inconscientes o de fuerzas sistémicas, sino que también es determinada por lo que Nagy llamó la "ética relacional", y planteó que para entender las conductas de las personas que están involucradas en relaciones cercanas, se necesita examinar el balance entre el dar y el recibir que existe entre ellas.

\section{METAS DE LA TC}

Varias son las metas que se han podido identificar que posee la TC. Para Nagy, Grunebaum y Ulrich (1991) una de las metas fundamentales de este modelo es la prevención, y junto a esta está la de beneficiar a todas aquellas personas que tienen un interés en los resultados del proceso terapéutico llevado a cabo. Para Krasner y Joyce (1995) otra de sus metas es lograr la sanidad a través del encuentro; a partir de que el gran anhelo del espíritu humano es ser encontrado. "Encontrado" aquí significa ser escuchado de manera genuina, sentirse considerado y haber sido abordado de manera directa por el otro.

De acuerdo con Goldenthal (1996), otra de las metas de este acercamiento psicoterapéutico está en poder ayudar a las personas a que se produzcan en ellas cambios significativos en la forma en que piensan sobre sus relaciones y en la forma en que actúan en las mismas, teniendo siempre presente que, al producirse estos cambios en las personas, la relación se volverá más equitativa y más satisfactoria para cada uno de los miembros de la misma.

Mientras que para Cotroneo (1986) el objetivo de este marco de trabajo es ayudar a que los miembros de una familia puedan encontrar un balance o equilibrio entre el dar y el recibir. Para van der Meiden, Noordegraaf y van Ewijk (2018) la TC tiene como objetivo principal restaurar las injusticias y mejorar el cuidado responsable dentro de las relaciones, así como procurar el bienestar del cliente y no solo provocar cambios en su conducta. También tiene como objetivo el cuidado de las generaciones futuras y el aumento de la confianza relacional de manera recíproca.

Ducommun y Reiter (2014) sostienen que la principal contribución que hizo Nagy al campo de la psicoterapia fue el haber hallado a partir de su trabajo clínico que la expectativa de justicia y reciprocidad en las relaciones cercanas es un determinante significativo del comportamiento de las personas hacia los demás; otra contribución fue el haber encontrado que la forma en que las personas tratan a los demás depende de lo que estas han recibido y de lo que se ha hecho por ellas.

Nagy y Krasner (1986) presentaron las cuatro dimensiones de la realidad relacional y en el año 2000, participando en la Conferencia Anual de la Asociación de Terapia Familiar de Hungría, Nagy propuso de manera oficial la quinta dimensión. Estas dimensiones son las siguientes: 1) Los hechos; 2) La psicología individual; 3) Los sistemas de patrones transaccionales; 4) La ética relacional y 5) El aspecto óntico de las relaciones.

Estas cinco dimensiones están entretejidas, pero de ellas la piedra angular de la TC de acuerdo a lo planteado por Nagy et al. (1991) es la cuarta dimensión, la de la ética relacional. También ha sido nombrada como: "ética de la mutualidad", "ética de la reciprocidad", "ética de la responsabilidad relacional", "ética de la responsabilidad por las consecuencias", "ética de la responsabilidad por las relaciones", "ética del mérito", "ética de la debida consideración" y "ética de la confianza merecida".

La ética relacional es la guía terapéutica de la TC y tiene que ver con el equilibrio o balance relacional, la equidad, la responsabilidad y la confiabilidad. Se basa fundamentalmente en: a) la equidad o imparcialidad, y b) un balance en movimiento que oscila entre las deudas y méritos mutuos de las partes involucradas en la relación. Esta dimensión se refleja en el cuidado recíproco, formulada como el equilibrio de dar y recibir mutuamente. En este balance o equilibrio en movimiento también se refleja la reciprocidad y la confiabilidad que se ha desarrollado en la relación. Se enfoca en crear confianza relacional actuando de manera equitativa. 
De acuerdo a Compton (1998) el fundamento de la ética relacional descansa sobre un valor de alcance universal: la supervivencia y la calidad de la existencia humana. Esta supervivencia y calidad de la existencia humana dependen, asimismo, de la integridad relacional (o el mantenimiento de relaciones saludables y posibles). Esta autora también planteó que en la inversión de confianza debe haber una disposición a cuidar, a tomar en cuenta las consecuencias que afectan al otro en el mundo relacional de cada persona.

La cadena conceptual bosquejada por dicha autora sugiere que en última instancia la supervivencia y la calidad de la vida humana descansa, en el fondo, sobre la disposición de invertir confianza, es decir, de cuidar al otro y de preocuparse por los beneficios y necesidades del otro, así como de asumir responsabilidad por las consecuencias que se derivan del relacionarse con el otro. El cuidar por tanto pasa a ser un elemento clave y de extrema importancia y significado para la teoría y práctica de la TC.

Nagy y Krasner (1986) endosan el planteamiento hecho por Compton relativo a la importancia del cuidado para la supervivencia y calidad de la vida humana, cuando plantean lo siguiente: "En resumen, entonces, la dimensión de la confianza merecida se fundamenta en el cuidado óntico con base en la interdependencia existencial" (p. 64). Sobre el significado del adjetivo óntico en la TC se especifica lo siguiente: "fue acuñado por Heidegger, y Spiegelberg (1960) lo define diciendo que designa 'una estructura inherente al Ser mismo" (Nagy, 1976, p. 60).

Para afirmar aún más lo expresado en los párrafos anteriores hay que decir que la TC descansa sobre dos presupuestos antropológicos. Uno de ellos es el de la "dependencia óntica" (Nagy, 1987, p. xvi). Esto es que las personas se necesitan unas a otras. Es decir, que existe una interdependencia entre ellas.

El segundo presupuesto antropológico de la TC es el cuidado óntico. van der Meiden et al. (2018) plantearon: "La teoría contextual se basa en el postulado de que las personas no solo se necesitan entre sí, sino que también tienen una tendencia innata a cuidarse unas a otras" (p. 4). Este presupuesto también fue expresado de la siguiente manera: "Según nuestra experiencia, la tendencia innata a preocuparse por otras personas es característica de los niños muy pequeños en lugar de limitarse a los padres o las figuras parentales" (Nagy \& Krasner, 1986, p. 78).

\section{EL CUIDADO COMO RECURSO EN LA TC}

Para Nagy y Krasner (1986) el cuidado es una de las piedras angulares de la TC, ya que es uno de sus presupuestos antropológicos fundamentales. De hecho, la ética relacional, que es la dimensión por excelencia de la TC, descansa sobre este cuidado. En referencia a este aspecto se puntualizó que este cuidado óntico, que en la TC implica la característica de ser un cuidado recíproco y responsable, está siendo estudiado en las recientes ciencias de la vida y los resultados de estas investigaciones "apuntan a la evidencia de posibles orígenes biológicos del cuidado recíproco que indican que cuidar a los débiles y vulnerables podría ser un elemento general en los seres vivos" (van der Meiden et al., 2018, p. 7).

Para van der Meiden et al. (2018) este presupuesto antropológico sobre el cuidado óntico, es decir, la tendencia innata a cuidarse mutuamente, se convierte en el recurso humano más importante en la TC, aun cuando no siempre esté visible, sino que se mantiene cubierto, oculto o latente en los seres humanos. Uno de los objetivos principales de la TC, con relación a este cuidado recíproco responsable, expresado de diferentes maneras consiste en: evocarlo, mejorarlo, provocarlo, divulgarlo, resaltarlo y enriquecerlo.

En la TC utilizar el cuidado recíproco responsable como recurso sirve para:

1. Mejorar el bienestar humano (a través de lograr el crecimiento de cada ser humano, aumentar la capacidad para la vinculación entre los miembros estrechamente relacionados y producir salud en cada uno de ellos)

2. Prevenir la disfunción en el futuro

3. Rehabilitar y reparar las heridas, las injusticias vividas en la familia

4. Fortalecer el "sistema inmunológico de la familia"

5. Aumentar el sustrato del destino de la posteridad

6. Generar un diálogo genuino 


\section{MÉTODO DE TRABAJO EN LA TC: LA PARCIALIDAD MULTIDIRECCIONAL}

La parcialidad multidireccional está considerada como el método de trabajo básico de la TC, (Nagy \& Krasner, 1986; Nagy, 1987; Nagy, Grunebaum, \& Ulrich, 1991; Nagy \& Ulrich, 1981; Goldenthal, 1996; Ducommun, 2002; Ducommun, 2014). Es el método que utiliza el terapeuta para guiar a los clientes hacia una nueva evaluación de las expectativas de los legados y hacia una mayor justicia y confianza entre los individuos. No solo es el método principal, sino también la principal actitud terapéutica.

Este método asume que más tarde o más temprano en el desarrollo del proceso terapéutico los terapeutas deben estar preparados para apoyar a cada uno de los miembros de la familia, presentes o ausentes. Entre los distintos objetivos de la parcialidad multidireccional está el proveer un paradigma que eventualmente pueda posibilitar que los miembros de la familia se escuchen y se respondan de manera mutua en sus propios términos.

Para Ducommun (2014) la parcialidad multidireccional es al mismo tiempo un método y una estrategia. Goldenthal (1996) desglosa el significado de la parcialidad multidireccional de la siguiente manera: $a$ ) Multi = muchos; $b$ ) Direccional $=$ dirigida hacia; $c$ ) Parcialidad $=$ favorecer a alguien. Este método conduce a tomar en cuenta la perspectiva de cada persona, y luego decidir quién necesita la parcialidad del terapeuta en un momento determinado. En este sentido, para este acercamiento la neutralidad es un mito.

En la TC se sostiene que para que un terapeuta contextual pueda aplicar la parcialidad multidireccional como método y actitud terapéutica que permita establecer una estructura que provea la seguridad para explorar, identificar, movilizar y ganar confianza residual es necesario que posea los siguientes elementos:

\subsection{Libertad}

Los terapeutas necesitan libertad y mentes que estén abiertas a los puntos de vista de otros cuyas vidas pueden verse afectadas por la acción terapéutica. Para lograr esto en la sala de terapia, tienen que ser capaces de lograrlo en sus relaciones con sus propias familias de origen, con sus hijos, compañeros, pares, colegas y otras personas con quienes comparten un compromiso mutuo.

\subsection{Convicción}

La culpabilidad o deserción existente puede ser la base de inhibiciones profundas en la vida y el contexto de una persona. Las personas pueden ser liberadas de la culpa existencial a través del derecho ganado. Las personas pueden desaprender la confianza excesiva en el derecho destructivo y descubrir cómo obtener un derecho constructivo como camino hacia la libertad y la satisfacción. Las personas se benefician al distinguir entre el significado de sus legados reales y las misiones y mandatos que se originan a partir de la delegación de los padres y la fuerza de la costumbre. Los terapeutas como profesionales obtienen derecho a través del beneficio de sus clientes.

\subsection{Coraje}

El coraje terapéutico, un requisito previo de la utilidad terapéutica, está involucrado de las siguientes maneras: Ayudar a una familia a enfrentar sus problemas reales de herida, vergüenza, dolor y bochorno. Hacer frente a los miembros de la familia con problemas aterradores, por ejemplo, incesto o suicidio. Asumir el riesgo de ser etiquetados erróneamente por colegas o clientes por tratar de aclarar los problemas de equidad de una familia. Desafiando la pseudo adversariedad que es defensiva y protectoramente reforzada en el proceso de ayudar a las personas a resolver los problemas reales de los conflictos de intereses de persona a persona. Enfrentando el fuerte impacto existencial y emocional de los conflictos de interés interpersonales. Enfrentar e interrumpir esquemas de negocios de tipo explotador entre miembros de la familia que destruyen la confianza interpersonal. Arriesgar la franqueza y persistencia que ayudan a los clientes a definir y representar posiciones y convicciones relacionales honestas.

\subsection{Conocimiento y Habilidades}

Una capacidad para reconocer los universales transculturales de mérito y obligación existencial, independientemente de las preferencias de valor aprendidas. Una capacidad para ayudar a las personas a enfrentar los balances de equidad entre ellos. Y una capacidad similar para identificar cómo los miembros de la familia utilizan su desarrollo moral e intelectual y su sofisticación como armas entre sí. Una capacidad para reconocer los problemas reales de la vida que crean profundas luchas interpersonales. Una capacidad para reconocer los puntos de ventaja realmente diferentes que 
las personas pueden sostener de forma natural y válida.

\section{5 y 4.6. Una capacidad de empatía y la habilidad para reclamar su propia existencia privada}

\begin{abstract}
Una capacidad para la parcialidad empática hacia todos los miembros de la familia libera las obligaciones de un terapeuta para con los clientes y le otorga el derecho a separar el trabajo de forma individual y a las relaciones personales. (Nagy \& Krasner, 1986, pp. 400-401).
\end{abstract}

A pesar de ser el cuidado uno de los dos presupuestos antropológicos y de ser un recurso sobre el que descansa este enfoque psicoterapéutico, hasta la fecha, no se ha definido ni se ha identificado este como uno de los elementos que debe poseer el terapeuta contextual para aplicar la parcialidad multidireccional. De hecho, Nagy y Krasner (1986) elaboraron un glosario compuesto por treinta y seis (36) conceptos considerados como básicos de la TC y en el mismo no aparece el concepto de cuidado.

A partir de lo expuesto hasta ahora, no queda la más mínima duda de la importancia que reviste este elemento (cuidar), no tan solo para la supervivencia y calidad de vida de los seres humanos, sino también para este acercamiento de cara al desarrollo de su teoría y práctica clínica.

\section{LA ÉTICA LEVINASIANA}

La propuesta filosófica de Emmanuel Lévinas está plasmada en la idea de que la ética es la filosofía primera. Según esta idea, la realidad básica del ser humano es su naturaleza moral, no su naturaleza racional. Esta naturaleza moral germina a partir del encuentro con el Otro en tanto que Otro. "Filosofía primera" significa una reflexión que no necesita nada previo que le dé sentido, entonces "ética como filosofía primera" implica que toda reflexión, meditación y pensar sobre lo que significa ser humano debe partir por una "ética" que no requiera una fundamentación para sostenerse por sí sola.

Critchley (2005), en su Introducción a Lévinas, expresa que la tesis de Lévinas está dominada por una gran idea "la relación con el otro no se puede reducir a la comprensión y que tal relación es ética" (p. 37). Señala también en dicho escrito que por "ética", en la tesis de Lévinas, se ha de entender "una relación de responsabilidad infinita hacia los demás" (p. 12). Esta relación también ha de ser asimétrica de manera radical. Para Putnam (2005) en la tesis de Lévinas hay dos ideas centrales que sirven de ejes transversales a todo el trabajo filosófico de Lévinas. Una es que ética implica una obligación hacia el otro y la otra es que dicha obligación fundamental es asimétrica.

La incidencia de su propuesta no solo se ha notado en el ámbito exclusivo de la filosofía, sino también en campos tan diversos como la psicología, la antropología, la teología, la sociología, la enfermería, la crítica, la práctica clínica psicoterapéutica y teoría literarias, entre otros campos y disciplinas, Orange (2012). Para los fines de este trabajo los temas de Lévinas que serán analizados son: El Otro y su rostro; La relación ética; $\mathrm{La}$ responsabilidad; La asimetría; y El sujeto ético levinasiano.

\subsection{El Otro y su rostro}

Sostiene el filósofo lituano que el error de occidente fue el haberse olvidado del Otro. En su propuesta lo importante no es la primacía del Mismo, sino la primacía del Otro. Es en la primacía del Otro donde se puede encontrar todo sentido posible. El Otro está por encima de mí, me tiene como rehén, me traumatiza. El Otro es quien me interpela y lo que hace que el Mismo despierte. El Otro levinasiano es otro por sí mismo. "Lo absolutamente Otro, es el Otro" (Lévinas, 2002, p. 63).

Cuando se recibe a ese Otro al mismo tiempo se le reconoce y reconocerlo es reconocer su hambre, su miseria, su vulnerabilidad, su sufrimiento. Y el mismo Lévinas (2002) hablando sobre el Otro, escribió: "El Otro que me domina en su trascendencia es también el extranjero, la viuda y el huérfano con los cuales estoy obligado" (p. 228).

El gran sentido del rostro para Lévinas es decir: "No matarás". Por tanto, el rostro habla y es lo que no se puede matar. Este "No matarás" es la primera palabra del rostro. Se convierte en una orden, en un mandamiento. En Lévinas el rostro adquiere una condición paradójica, por un lado, se convierte en el amo que manda y que espera que, por ser amo, el Mismo le obedezca. Si el Otro es amo, entonces el Mismo se convierte en esclavo. Pero al mismo tiempo es un rostro desprotegido. Esta desprotección del Otro a través de su rostro 
lo convierte en el pobre y en este caso si él es el pobre, entonces el Mismo es el rico. Frente a esta pobreza el Mismo expresa que por el Otro, él lo puede todo y es a quien le debe todo. El Mismo, por tanto, es aquel que frente a esta llamada del Otro a través de su rostro se la debe arreglar para poder identificar y buscar los recursos que necesita para responder a esta llamada.

En la propuesta levinasiana la primacía del Otro se convierte en el presupuesto de todas las relaciones humanas. El rostro no es más que una metáfora que Lévinas utiliza para que el Mismo le dé una respuesta a su demanda de que cumpla con el mandato ético de no dejarlo solo.

\subsection{La relación ética levinasiana}

En la propuesta del filósofo, ética es sobre todo relación. Relación con el Otro y para el Otro. En el planteamiento ético de Lévinas no hay necesidad de que exista un "porqué" para accionar. No existe un fundamento antes de la ética que la sostenga. Con relación a la utilización de la palabra ética en la propuesta de Lévinas es importante escuchar lo que el Maestro le comentó a Derrida en una conversación entre ambos. Critchley (2005) lo registró de la siguiente manera:

Lévinas dijo: "Usted sabe, para describir lo que hago a menudo se habla de ética, pero lo que me interesa después de que todo está dicho y hecho no es la ética, no sólo la ética. Es lo santo, la santidad de lo santo (le saint, la sainteté du saint)". (p. 39).

En esta relación ética hay un mandato ético para el "Yo" que le obliga, que le exige, que le ordena, que le manda a obedecer. Este obedecer tiene su raíz en el Infinito. Para entender a profundidad el sentido de la expresión "estoy obligado a decir aquí estoy para ti”, hay que entender qué significa en el contexto hebreo la expresión "heme aquí". "Heme aquí" en hebreo se expresa con el vocablo "Hineni" (pronúnciese jinéni).

Hineni significa ese "ponerse a disposición del otro sin reservas", ese "presentarse a sí mismo". Es la expresión que utilizó Abraham frente a Dios. "Aconteció después de estas cosas, que probó Dios a Abraham, y le dijo: Abraham. Y él respondió: Heme aquí (Hineni) (Génesis 22:1).

En el texto de Isaías también se encuentra la misma expresión: "Después oí la voz del Señor, que decía: ¿A quién enviaré, y quién irá por nosotros? Entonces respondí yo: Heme aquí (Hineni), envíame a mí (Isaías 6:8). Para el filósofo lituano cada sujeto está obligado a ponerse a disposición sin reservas ante las necesidades del otro, específicamente frente a su carestía, vulnerabilidad y sufrimiento.

El decir Hineni va acompañado de lo que Lévinas llama una responsabilidad infinita. La responsabilidad frente al otro es quizás el concepto clave que diferencia la ética levinasiana de los otros enfoques éticos que existen.

\subsection{La responsabilidad en la ética levinasiana}

La palabra responsabilidad (del latín respondere, que significa responder) se refiere a la obligación de responder por los propios actos. Normalmente este se ha entendido como referido al yo, que se dirige hacia sí mismo, es decir, ser responsable de sus propios actos. Para comprender en toda su dimensión el concepto de responsabilidad en la propuesta levinasiana es básico mirar el significado que esta palabra tiene para el judío. Uno de los mandatos entre los judíos establece que cada israelita es responsable del otro; en la propuesta de Lévinas esto significa que cada ser humano es responsable del otro.

Para Lévinas, el Yo está obligado a decir "estoy aquí/heme aquí" al Otro y asumir una responsabilidad infinita frente a él sin que le exija al Otro que haga lo mismo. En la tesis de Lévinas, la ética se entiende como responsabilidad, pero responsabilidad para con el otro. El Yo es responsable del Otro, responde por el Otro. En entrevista que le realizaran en el 1986 y que luego fue editada como texto, Lévinas expresó: "Lo que llamo serpara-el-otro, la palabra "responsabilidad", no es sino otra manera de expresarlo: soy responsable del otro, respondo del otro y, en suma, respondo antes de haber hecho cualquier cosa" (Guwy, 2006, p. 22). Responsabilidad para lo que no es asunto del Yo o que no le concierne. Lévinas es muy claro en lo que significa el alcance de la responsabilidad en la relación ética que plantea. Esto lo expresó de la siguiente manera:

Positivamente, diremos que, desde el momento en que el otro me mira, yo soy responsable de él sin ni siquiera tener que tomar responsabilidades en relación con él; su responsabilidad me incumbe. Es una responsabilidad que va 
más allá de lo que hago. (Lévinas \& Nemo, 2000, p. 80).

En la obra del Maestro, encontrarse con el Otro es una responsabilidad del Yo. Para él, el concepto de responsabilidad tiene tanto peso que en algunos momentos llegó a plantear la cuestión del amor en términos de responsabilidad. De hecho, sostuvo que la palabra amor era un término ambiguo y desgastado. Amor es "un 'hacerse cargo' del destino de los otros" (Lévinas, 2001, p. 129).

La responsabilidad en la propuesta de Lévinas, el responder al otro frente a su interpelación es clave para que el Yo encuentre su sentido. Es responsabilidad absoluta. Tal es el peso de dicho concepto que Lévinas expresó sobre el mismo esto: "Soy yo quien soporta todo. Conoce usted esta frase de Dostoievski: 'Todos nosotros somos culpables de todo y de todos ante todos, y yo más que los otros" (Lévinas \& Nemo, 2000, p. 83).

En la ética levinasiana, la responsabilidad también es un principio de individuación.

\subsection{La asimetría de la relación ética}

La otra idea central que atraviesa todo el pensamiento ético es la que se refiere a la asimetría de la relación ética. Una de las preguntas que le hace Nemo a Lévinas, en la conversación sostenida entre ambos, versa sobre este tema y a continuación Lévinas le responde de manera clara y precisa:

[Philippe Nemo] ¿Pero el otro no es también responsable con respecto a mí?

[Lévinas] Puede ser, pero esto es asunto suyo. Uno de los temas fundamentales de Totalidad e Infinito, del que aún no hemos hablado, es que la relación intersubjetiva es una relación asimétrica. En este sentido, yo soy responsable del otro sin esperar la recíproca, aunque ello me cueste la vida. La recíproca es asunto suyo. Precisamente, en la medida en que entre el otro y yo la relación es recíproca, yo soy sujeción al otro; y soy "sujeto" esencialmente en este sentido. (Lévinas \& Nemo, 2000, p. 82).

Al tocar el tema de la asimetría en Lévinas, Putnam (2005) señaló:

La tercera idea central en Lévinas, tan central que es difícil hallar algún lugar en el que Lévinas le responda a un interlocutor sin mencionarla, es la asimetría de la relación ética (...) el sine qua non levinasiano para entrar a la vida ética -lo que equivale a la vida humana, en cualquier sentido en que ésta sea "digno de ese nombre"- implica reconocer que se está obligado a ponerse a disposición de la necesidad del otro $\sin$ considerar a la vez que el otro también está obligado. (p. 73).

En la ética levinasiana el Yo que se hace responsable del otro no exige reciprocidad, porque si así lo hiciese entonces estaría convirtiendo su responsabilidad en una negociación, en igualdad y si esto pasa entonces, plantea Lévinas, no se ha entendido a cabalidad la afirmación de Dostoievski (Guwy, 2006).

En la entrevista que le hiciera Guwy a Lévinas en el 1986 aparece una pregunta directamente referida a este concepto:

\section{F. G. ¿Y qué ilustra lo que usted quiere decir con "asimetría"?}

E. L. La asimetría es ante todo el hecho de que mi relación conmigo mismo y mis obligaciones, tal y como las pienso, no están de entrada en una relación entre dos seres iguales en la que se supone que el otro sea yo mismo. Yo estoy ante todo obligado y él es ante todo a quien estoy obligado. No es en absoluto un extravío, es la modalidad esencial del encuentro con el otro (...) Es la vocación de la asimetría. (Guwy, 2006, p. 24).

\subsection{El sujeto ético levinasiano}

Sobre el Yo o Sí mismo de Lévinas (2003) este expresa de manera clara y precisa que "El término Yo significa heme aquí, respondiendo de todo y de todos" (p. 183). Y en otro de sus escritos escribe sobre el mismo tema lo siguiente:

Ser yo significa, por lo tanto, no poder sustraerse a la responsabilidad, como si todo el edificio de la creación reposara sobre mis hombros (...) la unicidad del yo es el hecho de que nadie puede responder en mi lugar. (Lévinas, 2009, p. 62).

Lo primero que hay que resaltar sobre este tópico es que el filósofo describe la subjetividad en términos éticos. Es en la ética donde se ata el nudo de lo subjetivo. Y la estructura básica que 
conforma esta subjetividad es la responsabilidad. Sobre este aspecto hizo este señalamiento: "En 'De otro modo que ser' hablo de la responsabilidad como de la estructura esencial, primera, fundamental, de la subjetividad" (Lévinas \& Nemo, 2000, p. 80). La subjetividad ética levinasiana no es para sí, sino para el otro. El sujeto ético levinasiano tiene la capacidad para llegar hasta la sustitución del otro. Asume el ser un rehén, se hace responsable del otro hasta el punto de expiar por el otro. Este sujeto ético sabe que tiene que rendir cuentas, sabe que tiene un compromiso, sabe que debe asumir una responsabilidad para con el otro. Sabe que tiene la obligación fundamental de que cumplir con el mandato ético de decirle al otro "heme aquí sin reservas para ti". Es una subjetividad abierta al compromiso con el otro. Es una subjetividad que se mueve hacia el exterior, que reconoce la alteridad del otro. Aprende que la diaconía es antes de cualquier diálogo. Se reconoce como un ser que responde a un llamado; su vocación suprema es el ocuparse del otro, es cuidar del otro. Sabe que tiene que responder a la llamada del otro, del otro que sufre, del otro que es vulnerable, del otro que vive en la indigencia y que con su sola mirada interpela a ese Yo. El sujeto ético en la relación ética se ha vuelto un ser sensible más que ser un sujeto consciente. En la ética levinasiana, el sujeto ético emerge, surge a partir de la llamada del otro y asume con hechos y acciones el dar respuesta a la misma. Sabe que puede matar al otro con su indiferencia, descuido y abandono, pero también sabe que el "no matarás" significa que tendrá la responsabilidad de hacer que el otro viva, porque donde no hay muerte lo que existe es la vida y ésta hay que protegerla y cuidarla.

El Yo levinasiano sabe que ha sido elegido para convertirse en guardián del hermano en la diacronía del tiempo. Frente a la pregunta que se le hace en donde se le pide que rinda cuenta del hermano, él responde "Sí, soy guardián de mi hermano". Lévinas (2001) asegura que frente a la pregunta que le hace Dios a Caín para que dé cuenta de su hermano Abel, la respuesta de Caín “¿Acaso soy yo el guardián de mi hermano?” es una respuesta sincera, pero carente de ética.

\section{DISCUSIÓN: APORTE DE LA ÉTICA LEVINASIANA AL CUIDADO EN LA TC}

El "encuentro" de Nagy con el tema del cuidado se dio a través de dos caminos. Uno de ellos fue a través de sus investigaciones, reflexiones y práctica clínica. Sobre este encuentro escribió lo siguiente:

Nuestra experiencia terapéutica incluye muchos años de trabajo casi exclusivo con familias y parejas, además de la anterior labor terapéutica individual (...) Hemos entrevistado familias de destacados profesionales, hombres de negocios y dirigentes comunitarios, así como familias de asesinos y desviados sexuales. Hemos atendido familias de hombres exitosos, de intelectuales, de trabajadores, y también de habitantes carenciados de los guetos. Pasamos cientos de horas en sus hogares y miles en nuestro consultorio. (Nagy \& Spark, 1994, p. 2).

El otro camino fue a través de su experiencia personal. Sobre este, en entrevista expresó lo siguiente:

Q: Nació en Hungría y se trasladó a América en el 1950. ¿Piensa que su vida personal ha influenciado su visión de la vida y de la terapia?

IBN: Probablemente ambos eventos han sido importantes. Personalmente pienso que la principal influencia ha sido que aún antes de entrar a la escuela de medicina ya estaba profundamente interesado en ayudar a los psicóticos. Aquí estaban sufriendo, sufriendo injustamente, seres humanos cuya condición era un misterio que ni la medicina ni la psicología habían resuelto. Así que, el desafío estaba allí para mí aun antes de la escuela de medicina.

Comencé mi formación médica sabiendo que perseguiría la psiquiatría. (Heusden \& Eerenbeemt, 1986, p. 3).

Este breve fragmento de entrevista, con la riqueza de información y de significado que contiene, puede ser parafraseado en los términos de la ética levinasiana de la siguiente manera: "Preocupación por ser cuidador del Otro, del Otro que sufre. El Otro que a través de su rostro llama e interpela para que se le dé respuesta -se asuma una responsabilidad infinita- a su sufrimiento".

En él también se pueden identificar espacios claves que abren sus puertas para dar la bienvenida a la ética levinasiana en la TC. Estos espacios son los siguientes: 


\subsection{El Paciente como el Otro que sufre ${ }^{1}$}

Resulta muy evidente identificar un punto de encuentro entre estos dos pensadores, y es que ambos fueron movidos por experiencias personales en donde el sufrimiento - propio y del otro- fue la característica esencial observada. Este sufrimiento marcó la vida y obra de ambos. A este respecto leamos lo que Putnam (2005) escribió sobre Lévinas:

\begin{abstract}
Lévinas sobrevivió a la Segunda Guerra Mundial en circunstancias difíciles y humillantes, en tanto su familia-salvo su mujer y su hija- pereció. Esta experiencia bien pudo haber configurado su convicción de que lo que se exige de nosotros es la "infinita" voluntad de estar disponible por y para el sufrimiento del otro. (p. 43).
\end{abstract}

En la relación terapeuta-paciente, el paciente, en términos de la ética levinasiana, es el Otro que sufre. Lévinas utiliza las categorías de "la viuda", "el huérfano" y "el extranjero" (desconocido) para referirse al Otro que sufre.

El paciente es el extranjero y como tal es el desconocido que sufre, es el otro desamparado que se muestra a través de su rostro. El paciente como el otro humano levinasiano se presenta y hace una demanda infinita, una exigencia infinita de atención, protección, preocupación, de desvelo, de provocar sosiego y de que se le brinde cuidado. El paciente, al igual que el vecino levinasiano, es el que preocupa antes de haber asumido algún compromiso con él. El rostro del paciente como metáfora, llama, pide, busca, exige, persigue, toma como rehén e interpela al terapeuta; si pide espera recibir, si busca espera encontrar y si llama espera que le respondan, que le den respuesta. Este rostro dicta un mandato ético que espera sea obedecido por el terapeuta y lo hace a través de la siguiente expresión: no me mates, no me dejes morir solo, no me abandones en medio de mi fragilidad, vulnerabilidad, lucha y sufrimiento. Esta expresión, que se puede leer en su mirada, es la primera palabra del rostro levinasiano del paciente. No abandonarlo implica que hay que cuidarlo, ya que lo que se cuida dura y mientras más se cuida más se posterga la muerte o desaparición del mismo. El precio del descuido o no atención al sufrimiento del paciente por parte del terapeuta tiene un precio muy caro para todos los que están siendo afectados por la situación presentada.

Pero al mismo tiempo este rostro que interpela, demanda, exige y toma como rehén, se deja ver y conocer como pobre, indefenso, vulnerable, con necesidades y carestías. Esta es la gran paradoja del rostro del paciente: un amo que manda y exige que le obedezcan, pero por otro lado es el que sufre, el indigente, el que está desnudo y devastado. El paciente sufre, se siente degradado, tiene necesidad, pero también está lleno de vergüenza por saber que es un ser necesitado y carenciado que solicita y demanda ayuda.

El paciente, como el otro levinasiano, adquiere la primacía en la relación terapéutica y por tanto está por encima del terapeuta. El paciente habla de su miseria, de su angustia, de su soledad, de las injusticias que ha vivido o que todavía está viviendo, pero todo este revelarse en confianza tiene como objetivo último que se le dé respuesta, es decir, que se asuma una responsabilidad infinita frente a lo que es y está viviendo. Su gran meta es que se le responda. En su dejarse conocer anhela hospitalidad por parte del terapeuta. En la ética levinasiana el Otro es el prójimo: el paciente es el prójimo.

\subsection{El terapeuta contextual como sujeto ético levinasiano y como cuidador del paciente (del otro que sufre)}

El quehacer del terapeuta contextual como sujeto ético levinasiano encuentra su base y punto de partida en el rostro del paciente que le ordena, le manda y le interpela para que dé respuesta a su sufrimiento, a su dolor, a su desnudez. Desde que recibe este mandato ético, el terapeuta se convierte en "rehén" del paciente, se sabe llamado, se siente interpelado y se siente perseguido por este mandamiento.

El mandamiento le obliga, le conmina a obedecer a la demanda ética que tiene por delante. No tiene escapatoria. Es tal la importancia que tiene que el terapeuta se convierta en un rehén que el mismo Lévinas planteó sobre este punto lo siguiente: "Es a través de la condición de ser un rehén que puede existir la piedad, la compasión, el perdón y la proximidad en el mundo -aún lo poco que hay, incluso el simple 'Después de usted, señor" (Lévinas, como se citó en Orange, 2013, p. 47). 
El mandamiento ético al terapeuta contextual es muy claro y preciso: Está obligado a responder, debe asumir una responsabilidad infinita, hacerse cargo del sufrimiento del paciente que dice: no me dejes solo en mi sufrimiento, soledad, porque estoy devastado y me siento muy vulnerable. El paciente presenta una exigencia infinita de necesidad, de protección y de cuidado, y este sufrimiento lo coloca por encima del terapeuta.

El terapeuta, con su respuesta, elimina por completo el ser indiferente frente al desconocido que tiene por delante y que sufre -el paciente-. En el momento en que reconoce que el otro con su necesidad y su demanda se coloca por encima de él, en ese preciso momento exclama sin expresarlo que se ha convertido en cuidador/guardián de éste. Debe señalarse, como el propio Lévinas en algunos momentos expresó, que existe la posibilidad de que no se responda a este mandato ético. Es posible ver al otro sufrir y pasar de largo sin hacer nada. El terapeuta sabe que está ligado al paciente con anterioridad a cualquier compromiso adquirido, el paciente ordena, demanda antes de ser reconocido.

En la responsabilidad que asume el terapeuta frente al mandamiento que se le ha dado y bajo la condición de vulnerabilidad que experimenta el paciente, este sujeto ético coloca en primer lugar esta condición y le da la bienvenida al paciente. Este responder conlleva un proceso.

Esta responsabilidad que asume frente al paciente que sufre no la eligió; él es elegido y por lo tanto es el único que puede hacer algo con relación a la demanda que tiene frente a sí. Es una obligación ética no de contrato. Su subjetividad queda marcada por su sentido de responsabilidad. Su vocación suprema es el ocuparse del que sufre, es cuidar del otro. Se ha vuelto un ser compasivo. Desde la ética levinasiana el verdadero sentido de su existencia y de su humanidad como terapeuta está en reconocer y actuar en función de la primacía que tiene el cliente.

\subsection{La relación terapéutica como relación ética levinasiana}

Esta relación terapéutica está marcada por una ética que:

a) Está dirigida al otro, al prójimo. Esta ética trasciende las relaciones cercanas. No se limita a las personas que están estrechamente vinculadas. Está dirigida al paciente como el otro que sufre. Este aspecto de la ética levinasiana queda muy bien aclarado con lo que Orange (2013) escribió sobre el mismo:

Existe la objeción de que cuando uno ama a alguien, uno no se siente obligado, tomado como rehén, traumatizado, perseguido por el otro, tal como afirmó Lévinas. Seguramente esto es cierto, pero Lévinas no estaba hablando de relaciones íntimas y personales, sino más bien de la viuda, el huérfano y el desconocido. Estaba hablando del paciente que aún no he llegado a querer, del vecino que vi siendo llevado a los campos de concentración, del vagabundo murmurando en el metro. Estaba hablando del hombre que se tiró a las vías del metro para salvar la vida de un desconocido, de los médicos sin fronteras y de todo aquel que disminuye la velocidad lo suficiente como para mantener la puerta abierta para otro.

“Apres vous, monsieur!”. (p. 57).

Tal y como ha sido planteado en la literatura sobre la relación terapéutica, las necesidades, carencias y sufrimientos del paciente que sufre son la razón de ser de este proceso, Orange (2013). Nagy y Krasner (1986) expusieron que "la terapia sería una ocupación errónea si una persona fuera insensible al sufrimiento de las personas" (p. 397). Dichos autores también fueron muy explícitos al sostener que una de las grandes encomiendas que tiene el terapeuta al ejecutar su trabajo desde la visión contextual está relacionada directamente con "ayudar a las personas que están sufriendo, incapacitadas o discapacitadas" (p. 275).

b) Es crítica. Esto es, que cuestiona la libertad y la autonomía del "Yo" del terapeuta. El terapeuta no es quien elige acercarse al paciente, todo lo contrario, es el paciente quien lo elige. Como ya ha sido planteado, el terapeuta se convierte en un "rehén" del paciente.

c) Está fundada en el otro; es decir, que tiene su punto de partida en el otro, que es con el otro y para el otro. Es una relación terapéutica que parte de la necesidad, del sufrimiento del paciente. El paciente, como el otro desconocido que sufre, a través de su rostro inicia la relación.

d) Presenta una radical asimetría entre el terapeuta y su cliente. Si esta relación es asimétrica entonces no hay espacio para esperar, desear o anhelar la reciprocidad. La asimetría está por encima de la reciprocidad. Critchley, (como se citó en Orange, 2013), planteó el sentido de la 
asimetría levinasiana de la siguiente manera: “en el interior de esa relación, mientras está teniendo lugar, en este preciso momento, colocas una obligación sobre mí que te hace más que yo, más que mi igual" (p. 45).

e) Es práctica. Es acción y no conceptualización. El sufrimiento del paciente no puede esperar hasta que el terapeuta lo comprenda ni pueda reducirlo a la comprensión. Es una relación "cara a cara" que busca cuidar, aliviar y no permitir que el paciente "muera solo".

f) Demanda una responsabilidad infinita de parte del terapeuta hacia el paciente como el otro que sufre. Bajo esta ética levinasiana el terapeuta en dicha relación asume una total responsabilidad por la condición del paciente que sufre. Significa que responde a la llamada que hace el paciente a través de sus necesidades y sus vulnerabilidades. El terapeuta tiene la obligación de ser el cuidador del paciente. Es el guardián del hermano, del prójimo, del paciente. Es el responsable del paciente sin haberlo elegido. El asumir una responsabilidad total e infinita por el paciente y su condición es la clave para que el Yo del terapeuta pueda encontrar su sentido y lugar de cara a su vocación de servicio. En la ética levinasiana el sentido de la vocación auténtica del terapeuta se da en la responsabilidad que este asume frente a la realidad del sufrimiento del paciente. Es una responsabilidad que va más allá de lo que el terapeuta hace. El terapeuta es responsable del paciente sin haber tenido que tomar responsabilidad alguna con relación al paciente.

\section{CONCLUSIÓN}

Tal y como fue planteado en la primera parte de este trabajo, uno de los presupuestos antropológicos de la TC es el de la tendencia innata a cuidarse mutuamente, pero hasta la fecha no ha sido propuesto el "cuidar" como uno de los elementos que debe poseer el terapeuta contextual para aplicar la parcialidad multidireccional. Si bien es cierto que la no-proposición de este elemento no ha impedido la aplicación del método de la parcialidad multidireccional por parte del terapeuta contextual, sí creemos que la inclusión del mismo: 1) enriquecería la labor o práctica del terapeuta contextual, y 2) haría más fecunda y productiva la puesta en práctica de dicho método. El cambio que aquí se propone, con la inclusión de este nuevo elemento en el quehacer del terapeuta contextual, va en consonancia con una de las partes de la dinámica que se genera en todo proceso de cambio, a saber, la de la superación: aparición de nuevos elementos y características en el proceso (lo que antes no estaba, ahora sí aparece como algo novedoso).

A partir de la presentación y del análisis realizado en las sesiones anteriores de varios de los constructos básicos que forman parte de la ética levinasiana, consideramos que esta ética posee la suficiente capacidad y congruencia teórica para aportar las características básicas que habrá de poseer este nuevo elemento. Esta ética, al igual que la ética de la TC, es fundamentalmente relacional. La ética levinasiana es responsabilidad infinita y total hacia el Otro, y en el contexto de la TC, el Otro es el paciente que sufre. Cuidar es hacerse responsable del Otro. Es tener la plena certeza de que, frente al sufrimiento del paciente, el terapeuta es el "Guardián/Cuidador" de ese prójimo.

Por tanto, se propone agregar a la lista de los seis elementos señalados como básicos para que un terapeuta contextual pueda llevar a cabo su misión a través del método y estrategia de la parcialidad multidireccional, un séptimo elemento: La Capacidad para ofrecer cuidado.

Esta capacidad como cuidador requiere poseer las siguientes características:

Ser sensible: Para ver la demanda infinita en el rostro del paciente; para escuchar la interpelación que este hace; para saber que él es el "rehén" y no otro; que él es el que soporta en esos momentos el edificio del otro. Es la sensibilidad para "ver" el problema del paciente y no seguir de largo como si no se ha visto nada. Sensibilidad para negarse a ser indiferente. Si el "ver" se lleva a cabo sin la sensibilidad necesaria, el proceso pierde su esencia y se convierte en pura técnica y teoría. Sensibilidad para prepararse para asumir una responsabilidad infinita y para darle paso al segundo momento de este proceso.

Estar a la disposición sin reservas: $\mathrm{La}$ disposición a decir: "Heme aquí para ti (Hineni)". Es una expresión que el terapeuta nunca llega a verbalizar pero que siempre está presente en su quehacer terapéutico. Esta expresión significa: Estoy a tu disposición sin reservas para responderte en tu dolor y miseria. Es la actitud que el paciente espera percibir cuando se encuentra con el terapeuta. Es el segundo acto de ese responder, de ese "hacerse cargo" del otro. Describe la atención plena y consciente de parte del terapeuta para 
reconocer que el otro existe, y por cuanto existe y sufre él está haciendo acto de presencia. Lleva al terapeuta a salir de sí mismo. Esta disposición sin reservas ve la relación terapéutica como un eterno presente: cada vez que me llames responderé "aquí estoy para ti”. Todo sufrimiento habla y pregunta: ¿Dónde estás?Y se ha de responder con el: Hineni. La raíz de la obediencia está en esta expresión que le obliga y le ordena estar a disposición para ir hacia el paciente, y hacerse cargo de él, cuidar de él y velar por él.

Mostrar hospitalidad en su dimensión ética y psicológica-emocional: En la hospitalidad ética hacia el paciente se le manda el mensaje de que su necesidad ha sido colocada en primer lugar. Aquí empieza a tomar cuerpo la primacía del otro en la relación terapeuta-paciente. Esta hospitalidad ética no mira si se ha llegado a un acuerdo con el paciente, no se cuestiona quién es el paciente ni qué hizo. No se le juzga, simplemente se le da la bienvenida. En la hospitalidad psicológica-emocional se le da la bienvenida al paciente para que aflore la confianza y el dolor, para que se dé apertura al dialogo.
Mostrar compasión: Como impulso, deseo y acción para aliviar, reducir o eliminar el sufrimiento del paciente. Mueve al terapeuta a la acción, a dar respuesta, según sus posibilidades y recursos. Significa también identificar todos los recursos que pueden estar a disposición de parte del paciente.

Por último, hay que resaltar que la TC sostiene una postura integradora y recíproca. Es integradora en el sentido de que busca ser inclusiva no exclusiva; es decir, que toma en cuenta e incluye las premisas significativas de todos los demás enfoques a la psicoterapia y sus posibles contribuciones, siempre y cuando estos enfoques estén interesados éticamente y sean contractualmente responsables en el sentido de que tomen en cuenta los intereses de todas las personas a quienes la terapia potencialmente va a afectar. Es recíproca en el sentido de que está abierta a que cualquier otro acercamiento psicoterapéutico pueda beneficiarse de las contribuciones que ella haya realizado o del enriquecimiento que esté realizando o que pueda realizar. 


\section{Referencias}

Boszormenyi-Nagy, I. (1976). Una teoría de relaciones: experiencia y transacción. En I. Boszormenyi-Nagy \& L. Framo (Eds.), Terapia Familiar Intensiva: Aspectos Teóricos y Prácticos (pp. 56-115). México: Trillas.

Boszormenyi-Nagy, I. (1987). Contextual therapy: therapeutic leverages in mobilizing trust. In I. Boszormenyi-Nagy (Ed.), Foundations of contextual therapy: Collected papers of Ivan Boszormenyi-Nagy, MD. (pp. 191-212). New York: Brunner/Mazel.

Boszormenyi-Nagy, I., Grunebaum, J., \& Ulrich, D. (1991). Contextual therapy. In A. Gurman \& D. Kniskern (Eds.), Handbook of Family Therapy, Vol. II (pp. 200-238). New York: Brunner/Mazel.

Boszormenyi-Nagy, I. \& Krasner, B. (1986). Between give and take: A clinical guide to contextual therapy. New York: Brunner/Mazel.

Boszormenyi-Nagy, I. \& Spark, G. (1994). Lealtades invisibles. Reciprocidad en terapia familiar intergeneracional. Buenos Aires: Amorrortu.

Boszormenyi-Nagy, I. \& Ulrich, D. (1981). Contextual family therapy. In A. S. Gurman \& D. P. Kniskern (Eds.), Handbook of Family Therapy (pp. 159-186). New York: Brunner/Mazel.

Cotroneo, M. (1986). Families and abuse. In M. A. Karpel (Ed.), Family Resources: The Hidden Partner in Family Therapy (pp. 72-93). New York: Guilford.

Critchley, S. (2005). Introducción a Levinas. En E. Lévinas, Difícil libertad. Ensayos sobre el judaísmo (pp. 11-41). Buenos Aires, Argentina: Fundación David Calles.

Ducommun-Nagy, C. (2002). Contextual therapy. In F. Kaslow (Ed.), Comprehensive Handbook of Psychotherapy, Vol. III (pp. 463-487). New York: John Wiley, \& Sons.

Ducommun-Nagy, C. \& Reiter, M. (2014). Contextual therapy. In M. Reiter (Ed.), Case Conceptualization in Family Therapy. New Jersey: Pearson.

Goldenthal, P. (1996). Doing contextual therapy. New York: W.W. Norton \& Company.
Guwy, F. (2008). La asimetría del rostro. Entrevista a Emmanuel Lévinas. En A. Martos (Ed.), Emmanuel Lévinas: La filosofía como ética (pp. 17-27). España: Universidad de Valencia.

Heusden, A. \& Eerenbeemt, E. (1986). Balance in motion: Ivan Boszormenyi-Nagy and his vision of individual and family therapy. New York: Brunner/Mazel.

Krasner, B. \& Joyce, A. (1995). Truth, trust, and relationships: healing interventions in contextual therapy. New York: Brunner/Mazel.

Lévinas, E. (2001). Entre nosotros. Ensayos para pensar en otro. Valencia, España: Pre-Textos.

Lévinas, E. (2002). Totalidad e infinito. Ensayo sobre la exterioridad. Salamanca, España: Sígueme.

Lévinas, E. (2003). De otro modo que ser o más allá de la esencia. Salamanca, España: Sígueme.

Lévinas, E. (2009). Humanismo del otro hombre. México: Siglo xxi.

Lévinas, E. \& Nemo P. (2000). Ética e infinito. Madrid: La balsa de la Medusa.

Orange, D. (2012). Pensar la práctica clínica. Santiago de Chile: Cuatro Vientos.

Orange, D. (2013). El desconocido que sufre. Santiago de Chile: Cuatro Vientos.

Putnam, H. (2005). Levinas y el judaísmo. En E. Lévinas, Difícil libertad. Ensayos sobre el judaísmo (pp. 43-77). Buenos Aires, Argentina: Fundación David Calles.

Solé, J. (2016). Lévinas. La ética del otro. Madrid: ESPA. Recuperado de https://es.scribd.com/document/343531748/ Levinas-Joan-Sole.

van der Meiden, J., Noordegraaf, M., \& van Ewijk, H. (2018). Relational ethics as enrichment of social justice: Applying elements of contextual therapy to social work. Qualitative Social Work. doi: https://doi.org/10.1177/1473325018800383 


\section{Notas al final}

1 Nos permitimos usar la licencia retórica de ver al Otro levinasiano y su rostro como si fuera un paciente a la luz de lo expresado por el mismo Lévinas (2002) cuando escribió: "El Otro que me domina en su trascendencia es también el extranjero, la viuda y el huérfano con los cuales estoy obligado" (p. 228). 